Julio- Diciembre 2017

Año 10.

Revista de Investigación

Núm. 26

Académica sin Frontera

ISSN: 2007-8870

\title{
http://revistainvestigacionacademicasinfrontera.com
}

Recibido el 24 de mayo de 2017. Dictaminado favorablemente mediante arbitraje el 23 de septiembre de 2017.

\section{Evaluación del Clima Organizacional en las MIPYMES de Un Centro Comercial de Navojoa, Sonora.}

Marisol Galaviz Zamora. Maestra en Administración y Desarrollo de Negocios Instituto Tecnológico de Sonora. Callejon Capohuiza No. 1006. Col. Deportiva mar.galaviz@gmail.com

Itzel Yuelny López Rábago. 8vo. Semestre de Licenciado en Administración. Instituto Tecnológico de Sonora.

Fracc. Jacarandas N. 98 Navojoa, Sonora.

Itzel_yuleni@hotmail.es

Amarillas Ibarra, Priscilia Rossel. Maestra en Administración y Desarrollo de Negocios, Instituto Tecnológico de Sonora. Ave. Cocorit No.106. Colonia Sonora. priss.amarillas@hotmail.com

\section{RESUMEN}

El clima organizacional se identifica como el ambiente que se vive en la empresa o percepciones de los trabajadores de una organización, en esta influyen algunas dimensiones, como pueden ser la comunicación, la motivación, el liderazgo y el trabajo en equipo. La evaluación del clima organizacional, se orienta a la identificación de aspectos internos de la organización de carácter formal e informal para analizar cómo éstos afectan el comportamiento de los empleados, a partir de sus percepciones y actitudes, además de la forma que influyen en su motivación laboral (Méndez, 2006). Es de gran importancia evaluar 


\section{http://revistainvestigacionacademicasinfrontera.com}

la percepción del clima organizacional en los trabajadores de una empresa, ya que una persona que percibe un clima negativo, puede ser una persona con nivel bajo de productividad, y muchos de los problemas que se presenta en una organización es por el mal clima que se vive o que los colaboradores perciben de la empresa. A la luz de lo anterior surge la siguiente interrogante: ¿Cuáles son las características del clima organizacional en las pequeñas y medianas empresas?. El presente estudio se realizó con una muestra de 50 trabajadores de MIPYMES establecidas en un centro comercial de la ciudad de Navojoa, Sonora. EL instrumento utilizado fue diseñado y validado a través de un proyecto de investigación de maestría que lleva por nombre "Diseño y validación de un instrumento para evaluar el clima organizacional de las pequeñas y medianas empresas”, Amarillas (2013). El instrumento de clima organizacional está compuesto de 31 preguntas, en donde se hace referencia a la percepción que tiene el trabajador del clima organizacional en las siguientes dimensiones: liderazgo, trabajo en equipo, comunicación, motivación, organización, valores y cultura y toma de decisiones.

\section{Palabras claves: Clima organizacional, MIPYMES y características.}

\section{INTRODUCCIÓN}

El clima organizacional se identifica como el ambiente que se vive en la empresa o percepciones de los trabajadores de una organización, en esta influyen algunas dimensiones, como pueden ser la comunicación, la motivación, el liderazgo y el trabajo en equipo. Para las empresas o instituciones, hoy en día, resulta importante conocer el clima organizacional y medirlo, ya que este puede impactar significativamente en los resultados organizacionales. 


\section{http://revistainvestigacionacademicasinfrontera.com}

Para (Schneider, 1994) la definición de clima organizacional se considera un constructo complejo, debido a que implica la atmósfera percibida por los empleados, la cual ha sido creada por las prácticas, procedimientos y recompensas típicas de la organización; por otra parte según (Hellrieger \& Slocum, 1974) mencionan que el Clima Organizacional viene a ser "un conjunto de atributos que pueden ser percibidos acerca de una organización particular y/o sus subsistemas, y que puede ser inducido por la forma en que la organización interactúa con sus miembros y su ambiente”.

Según (Margarita Chiang Vega, 2010) menciona que el Clima organizacional radica en las personas, tanto en su conducta como en sus sentimientos. Además, Serra y Bugueño (2003), mencionan la importancia de mantener un clima organizacional óptimo y una buena calidad de vida de los trabajadores de las PyMES (Pequeñas y medianas empresas), en todos los niveles, ya que de eso depende el buen desempeño de los trabajadores.

El clima organizacional se preocupa por el recurso humano de la empresa, conocer que motiva y desmotiva al trabajador, para dar lo mejor de sí, por lo que es importante investigar el clima organizacional, ya que el ambiente laboral de una empresa es un factor que tiene gran incidencia en el desempeño y en la productividad del empleado. La conducta de un trabajador puede tener como resultado actitudes negativas o positivas que influyen en el desarrollo de las actividades organizacionales y en desempeño del personal.

Según (Mendez, 2006) la evaluación del clima organizacional, se orienta a la identificación de aspectos internos de la organización de carácter formal e informal para analizar cómo éstos afectan el comportamiento de los empleados, a partir de sus percepciones y actitudes, 
Año 10.

Revista de Investigación Núm. 26

\section{http://revistainvestigacionacademicasinfrontera.com}

además de la forma que influyen en su motivación laboral. Según (Brunet, 2007), el cuestionario escrito es el instrumento de medida más utilizado para la evaluación del clima. Esta herramienta contiene una serie de preguntas que describen hechos particulares de la organización, en donde los empleados encuestados deben indicar hasta qué punto están de acuerdo con la descripción mencionada.

García y Bedoya (1997), comentan que dentro de una organización existen tres estrategias para medir el clima organizacional:

1. Observar el comportamiento y desarrollo de sus trabajadores.

2. Realizar entrevistas directas a los trabajadores.

3. Realizar una encuesta a todos los trabajadores a través de un cuestionario.

García (1987) diseñó un "Modelo para el diagnóstico del clima organizacional", centrado en lo que siente o piensa el personal de la organización en aspectos tales como el reconocimiento que tienen acerca de su empresa, su organización y sus objetivos, la percepción que tienen acerca del medio en el cual desempeña sus labores, y del grado de desarrollo personal que prevé alcanzar al estar dentro de la empresa. El instrumento utilizado permite al encuestado expresar sus sentimientos a través de 17 preguntas, cuyas respuestas conducen al establecimiento de un perfil y a encontrar soluciones para mejorar el ambiente de acuerdo respuestas específicas como por ejemplo: fijar metas para mejorar el clima a través de la corrección de situaciones que resulten altamente negativas, fijar metas para mejorar el ambiente como un todo y tener una base para comparar el cambio del clima organizacional en el tiempo y para otros usos. 


\section{http://revistainvestigacionacademicasinfrontera.com}

De acuerdo con Méndez (2006), en 1977 John Sudarsky, profesor de la Universidad de los Andes, desarrolló en Colombia un instrumento de diagnóstico del clima organizacional llamado TECLA, el cual está fundamentado en la teoría de la motivación de McClelland y Atkinson, en donde se identifican las necesidades de afiliación, poder y logro. Tuvo también en cuenta las variables definidas por Litwin y Stringer, consideradas como dimensiones del clima organizacional (conformidad, responsabilidad, normas, recompensas, claridad institucional, espíritu de grupo, seguridad y salario).

Una investigación realizada por Salgado, Remeseiro \& Iglesias (1996) tiene como objetivo principal presentar los resultados de un estudio sobre el clima organizacional con la particularidad de que dicho estudio se efectuó en una en una pequeña empresa, acorde con las características de la estructura empresarial. En una empresa comercializadora de automóviles. Los resultados mostraron, que los empleados perciben que la dirección los apoya y les estimula a conseguir un trabajo en equipo y apoyarse entre sí, permitiéndoles al propio tiempo cierto grado de autonomía y auto organización y existiendo normas claras de actuación y admitiéndose nuevas propuestas..

Otra investigación realizada por Pelekais, Navay \& Tirado (2006) tuvo como objetivo determinar la influencia de la Inteligencia Emocional sobre Clima Organizacional en los niveles gerenciales medios de las PYMES. Los resultados permiten plantear que los elementos evaluados de la Inteligencia Emocional que se encuentran presentes en el Clima Organizacional y que en cierta forma lo afectan, se encuentran la motivación y las habilidades sociales.

Por eso es de gran importancia evaluar la percepción del clima organizacional en los trabajadores de una empresa, ya que una persona que percibe un clima negativo, puede ser 


\section{http://revistainvestigacionacademicasinfrontera.com}

una persona con nivel bajo de productividad, y muchos de los problemas que se presenta en una organización es por el mal clima que se vive o que los colaboradores perciben de la empresa.

La evaluación del clima organizacional es comúnmente realizada en grandes empresas, dejándose de lado en las Micro, pequeñas y medianas empresa (MIPYMES), Actualmente existen alrededor de 5 millones 32 mil 503 empresas en México, según datos estadísticos del Instituto Nacional de Estadística y Geografía (INEGI, 2016), de los cuales 4 millones 48 mil 543 son Mipymes (INEGI, 2015) que representan el 80.45\% del total de empresas en el país; respecto a sonora, el secretario de economía Gómez (2014, Párr.2, citado en Miranda y González, 2015), señaló que "de cada cien empresas sonorenses, 98 son micro, pequeñas o medianas empresas"

De acuerdo con datos estadísticos en México 8 de cada 10 empresas desaparecen en los primeros dos años, otro dato de interés es el que explica la relación entre longevidad y tamaño de la empresa, entre más grande sea la compañía mayor es su duración, del total de grandes empresas en el país el 59.85\% tienen más de 15 años de antigüedad, tasa que se reduce en las medianas empresas al $58.75 \%$ y en las micro y pequeñas empresas alcanza el $39.07 \%$ (Tellaeche, 2013).

A la luz de lo anterior puede observarse que es necesaria la evaluación del clima organizacional en las MIPYMES. Por lo que se plantea la siguiente interrogante: ¿Cuáles son las características del clima organizacional en las pequeñas y medianas empresas de un centro comercial de Navojoa, Sonora.? 


\section{http://revistainvestigacionacademicasinfrontera.com}

\section{DESARROLLO:}

\section{Metodología}

La presente investigación es de tipo cuantitativo, de alcance descriptivo, transversal, con diseño no experimental (Münch y Ángeles, 2007; Hernández, Fernández, y Baptista, 2006).

Esta investigación es de tipo no experimental ya que se realiza sin la manipulación deliberada de variables y en los que sólo se observa los fenómenos en su ambiente natural para después analizarlos. Así mismo, se realiza un estudio transversal, debido a que se estudia el clima organizacional en un periodo específico del tiempo, no generalizando ni aplicando los datos presentados a situaciones futuras (Münch y Ángeles, 2007; Hernández et al., 2006).

Por otra parte, el alcance de la investigación es descriptivo, es decir, busca especificar las características y rasgos importantes del clima organizacional de las Pymes de acuerdo al periodo en el que se efectuará la investigación (Hernández et al., 2006).

El presente estudio se realizó con una muestra de 50 trabajadores, de los cuales el $76 \%$ son mujeres y solamente el $22 \%$ son hombres, mismos que se encuentran en 3 distintos rangos de edad los cuales son de 20 a 30 años en donde se presenta un $78 \%$ de los encuestados, de 31 a 40 años tenemos alrededor del 8\% y dentro del rango de edad de 41 a 50 años contamos con un $12 \%$. De igual manera se encuentran en 2 estados civiles el $68 \%$ es soltero y el $28 \%$ casado.

El instrumento utilizado para la presente investigación, fue diseñado y validado a través de un proyecto de investigación de maestría que lleva por nombre "Diseño y validación de un 


\section{http://revistainvestigacionacademicasinfrontera.com}

instrumento para evaluar el clima organizacional de las pequeñas y medianas empresas", Amarillas (2013). El instrumento de clima organizacional está compuesto de 31 preguntas, en donde se hace referencia a la percepción que tiene el trabajador del clima organizacional en las siguientes dimensiones: liderazgo, trabajo en equipo, comunicación, motivación, organización, valores y cultura y toma de decisiones.

Para las respuestas, se manejó una escala de Likert, con cuatro opciones: 1. Nunca, 2. Pocas veces, 3. Algunas veces 4. Casi siempre, 5. Siempre. Dentro de una escala de 1 a 5, en donde el 1 representa la peor forma en la que el factor de manifiesta y el 5 su manifestación ideal o deseable. En cada una de las encuestas se incluye el área de trabajo al que pertenece cada trabajador, sexo, situación laboral y rangos de edades. Así como el objetivo de la encuesta y las instrucciones de la misma.

De igual manera, para medir la fiabilidad del cuestionario, se realizó la determinación del coeficiente Alfa de Cronbach, esto a través del programa SPSS (Statistical Package for the Social Sciences), en donde se obtuvo un coeficiente de Alfa de 0.932, esto indica que el sujeto en estudio reconoce la dimensión o el factor que se está evaluando.

Una vez seleccionado el instrumento y adecuado al contexto de la investigación, se procedió a la aplicación y tabulación del mismo mediante el paquete estadístico SPSS, (Statistical Package for the Social Sciences). Finalmente se analizaron cada una de las dimensiones que integran el cuestionario, de tal forma que se asegura la correcta medición de cada variable y permitan su veracidad en la información adquirida para la presentación e interpretación de los resultados. 


\section{http://revistainvestigacionacademicasinfrontera.com}

\section{Resultados y discusión}

Una vez desarrollada la metodología se continuó con la interpretación de los resultados, mismos que se obtuvieron en consideración a las percepciones de los trabajadores que dieron respuesta al cuestionario.

En la dimensión de Liderazgo se encontró que el 92\% de las personas encuestadas perciben que existen un buen liderazgo en la empresa, debido a que consideran que existe una buena relación con sus jefes, así mismo, les es fácil seguir las instrucciones que se les dan y mencionan que los jefes tratan con respeto al personal, por otra parte; el otro $8 \%$ dice no estar de acuerdo ya que los jefes no especifica claramente cual son las actividades que se tienen que cumplir.

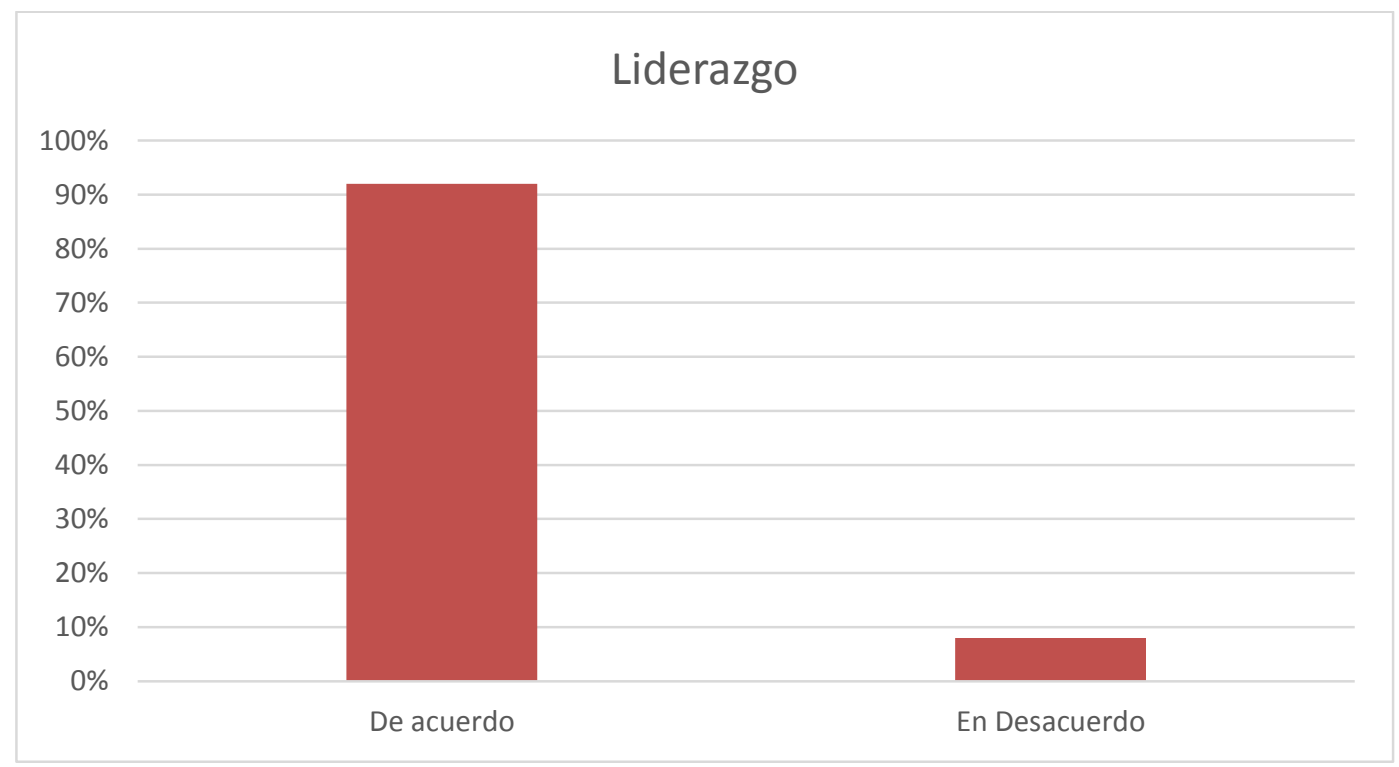

Tabla 1 Dimensión Liderazgo 


\section{http://revistainvestigacionacademicasinfrontera.com}

Por otra parte, el 93\% de los encuestados considera que el trabajo en equipo, es una dimensión evaluada de manera positivamente, ya que expresan que cuando se presenta un conflicto tratan de buscar la mejor manera de solucionarlo y tienen claro que trabajar en equipo ayuda a obtener mejores resultados, el otro 7\% dice no estar de acuerdo con esta dimensión, ya que comentan que algunos integrantes no tienen claras sus actividades.

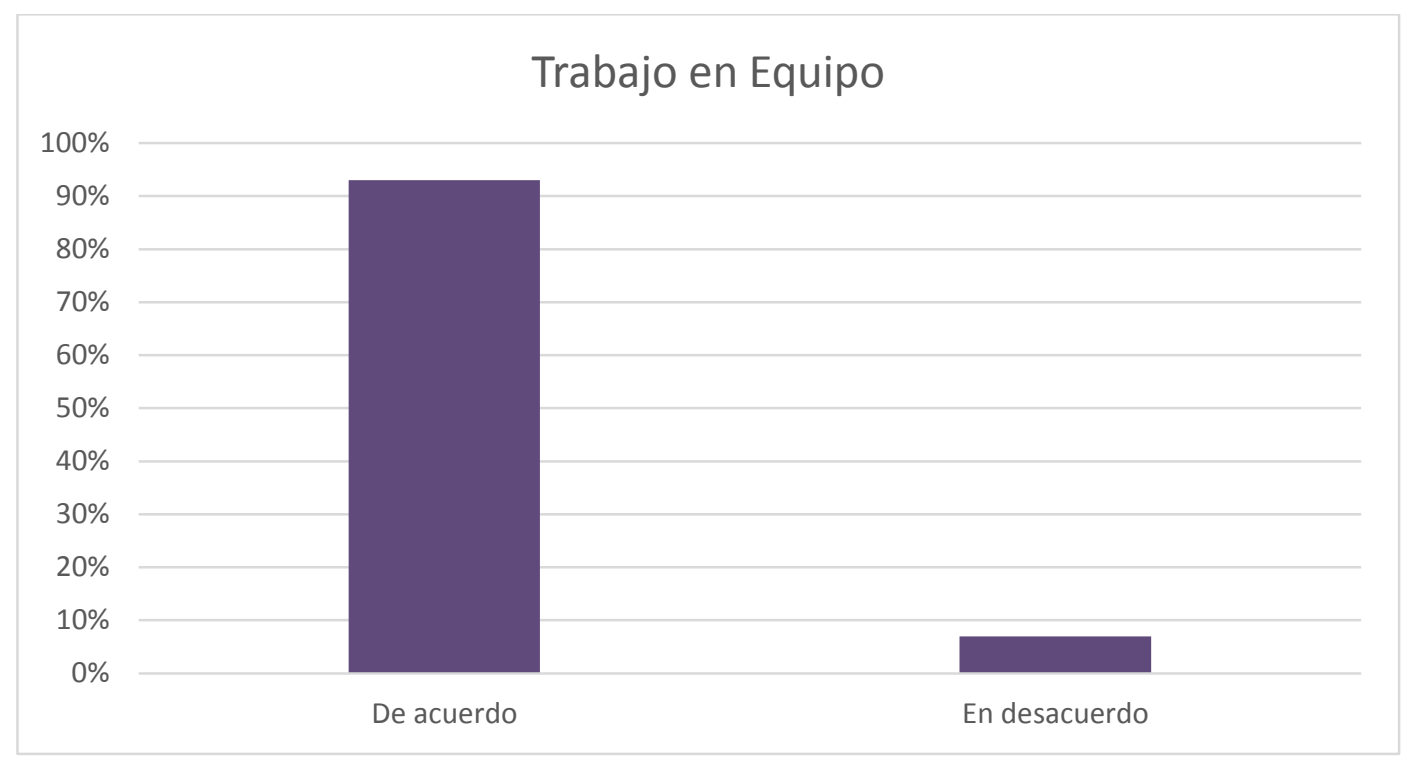

Tabla 2 Dimensión Trabajo en Equipo

De las personas encuestadas el $83 \%$ contestaron que perciben una buena comunicación, ya que consideran que los empleados son informados de acontecimientos importantes de la empresa, y conocen sus derechos y obligaciones, así mismo, consideran tener clara la forma de evaluar el desempeño de los empleados y se definen de manera clara las metas que se deben lograr en el trabajo; solo el 17\% mencionó no estar de acuerdo en que exista una buena comunicación debido a que consideran que no tienen la libertar de expresar sus ideas. 
Julio- Diciembre 2017

Revista de Investigación

Año 10.

Académica sin Frontera

Núm. 26

ISSN: 2007-8870

\section{http://revistainvestigacionacademicasinfrontera.com}

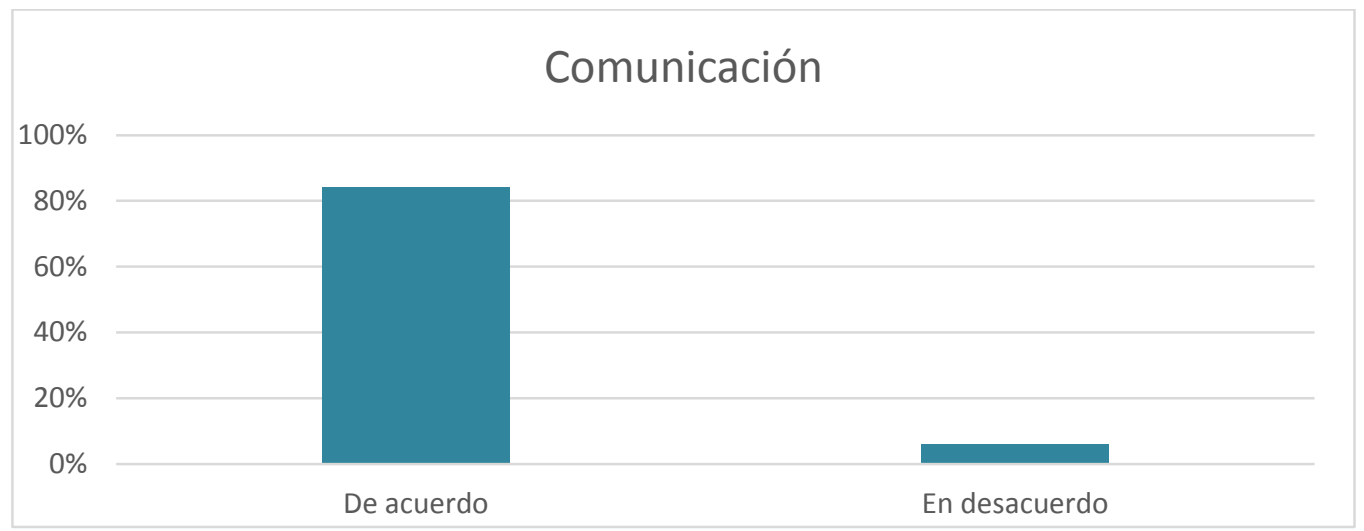

En cuanto a la dimensión de motivación, se puede definir que el $79 \%$ de las personas Tabla 3 Dimensión Comunicación consideran que reciben un buen trato por parte de sus compañeros de trabajo, y mencionan que cuentan con un área de trabajo en óptimas condiciones, de igual manera, se les recompensa justamente su desempeño en el trabajo y existe un buen equilibrio entre la vida personal y laboral, lo que trae como consecuencia un alto nivel de motivación en el personal. El $21 \%$ considera no estar motivado, ya que la empresa no les permite asistir a eventos personales dentro de su jornada laboral, lo que es considerado un limitante importante para su satisfacción personal. 
Julio- Diciembre 2017

Revista de Investigación

Año 10.

Académica sin Frontera

Núm. 26

ISSN: 2007-8870

\section{http://revistainvestigacionacademicasinfrontera.com}

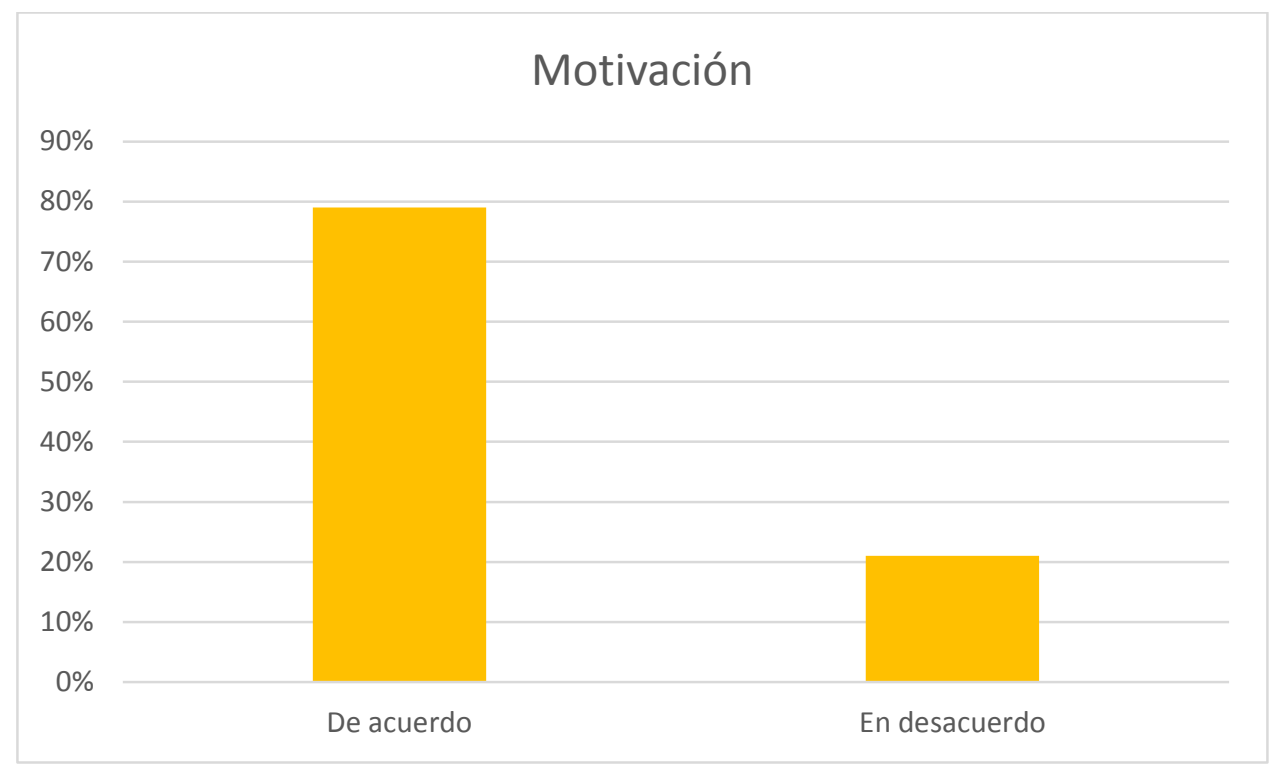

Tabla 4 Dimensión Motivación

Por otro lado, de las personas encuestadas el $93 \%$ considera que existe una buena organización en la empresa, ya que los empleados pueden identificar claramente en que puesto de trabajo se encuentran dentro de la organización, de igual manera les es suficiente su horario de trabajo para realizar sus actividades laborales. Pero el otro $7 \%$ de las personas encuestadas consideran que no existe una buena colaboración por parte de sus compañeros de trabajo, eso puede ser un problema para el logro de objetivos de la empresa. 
Julio- Diciembre 2017

Revista de Investigación

Año 10.

Académica sin Frontera

Núm. 26

ISSN: 2007-8870

\section{http://revistainvestigacionacademicasinfrontera.com}

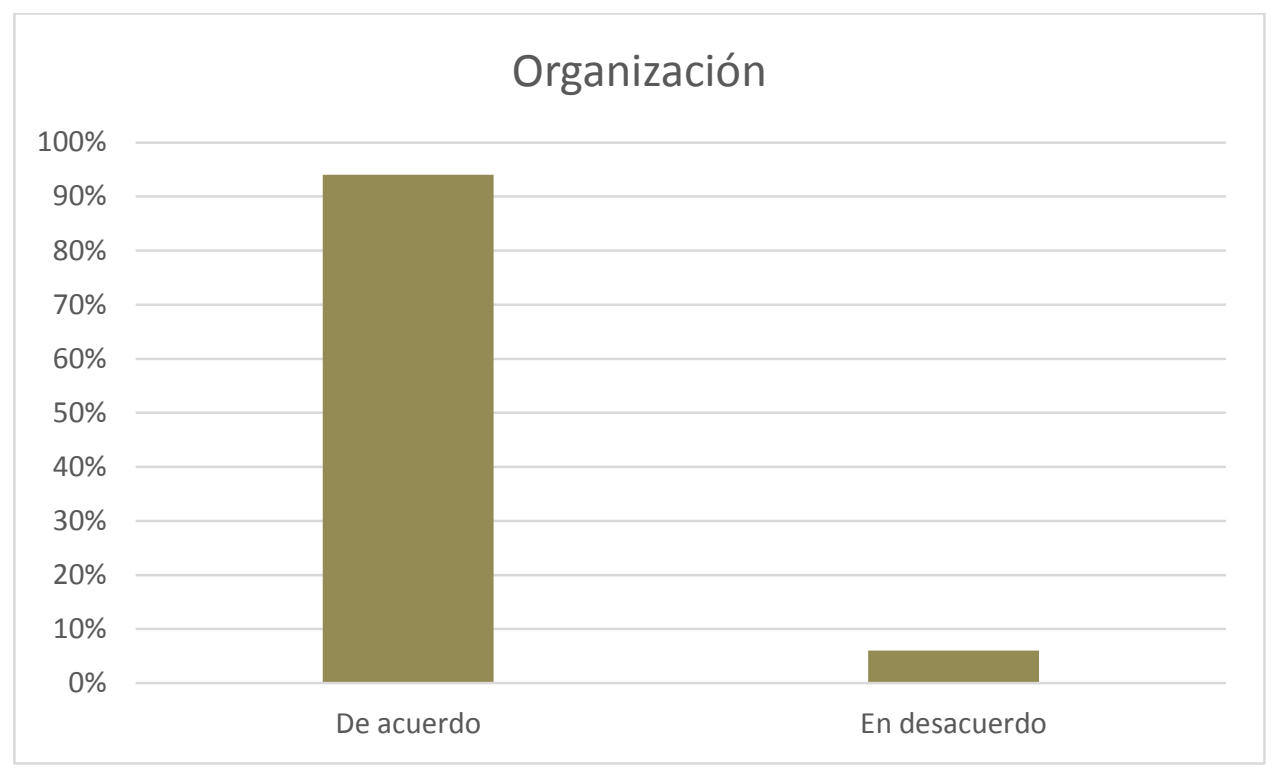

Tabla 4 Dimensión Organización

En la dimensión de valores y cultura el $84 \%$ considera los empleados de la empresa conocen la misión, visión y valores de la empresa, de igual manera mencionan que se promueve el respeto mutuo entré los trabajadores de la organización. Por otra parte el 16\% dicen no estar de acuerdo; ya que ellos no se sienten identificados con la empresa, esto puede ser debido a la falta de motivación por parte de la empresa. 
Julio- Diciembre 2017

Revista de Investigación

Año 10.

Académica sin Frontera

Núm. 26

ISSN: 2007-8870

\section{http://revistainvestigacionacademicasinfrontera.com}

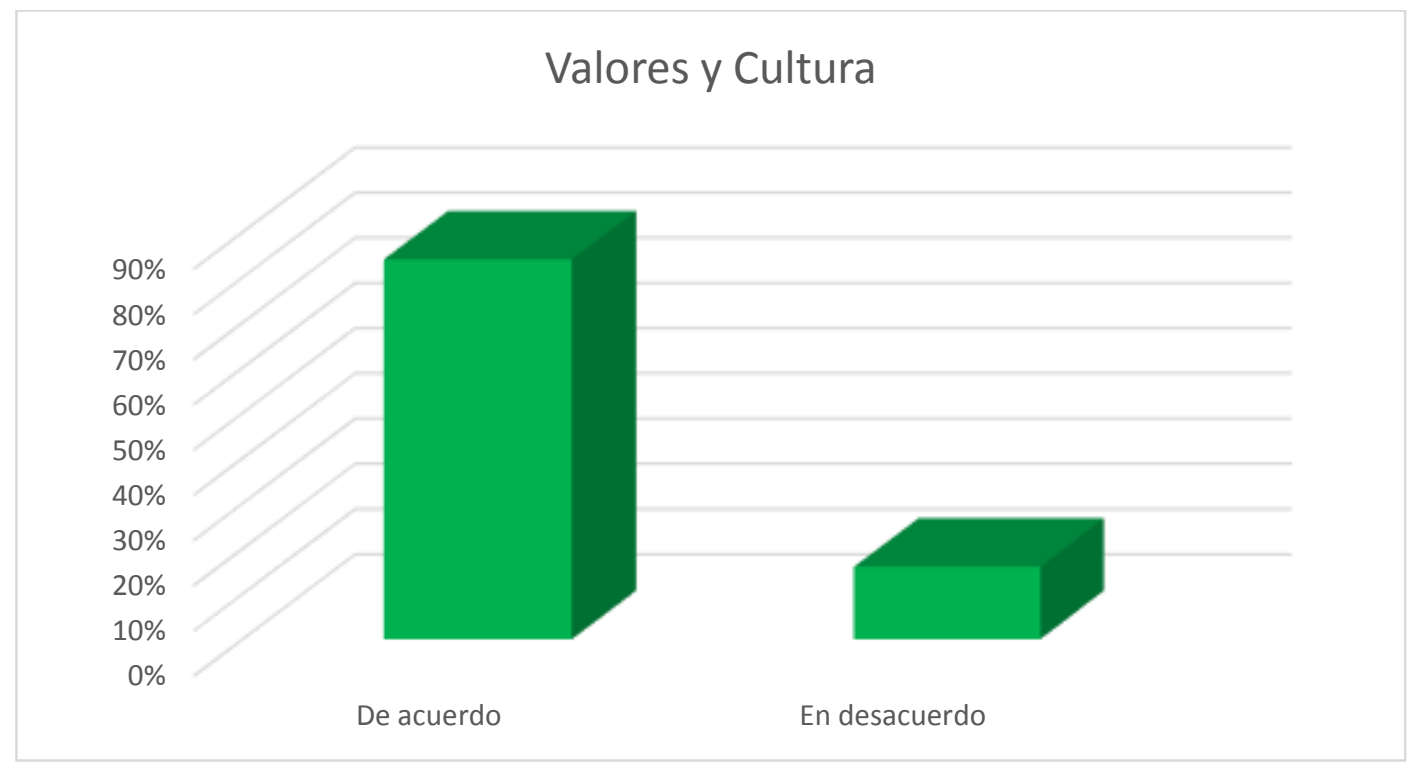

Tabla 5 Valores y Cultura

La personas consideran el $74 \%$ que en la empresa se realiza una buena toma de decisiones, por lo que mencionan que las decisiones son apoyadas por los miembros del equipo de trabajo, de igual manera dicen que las decisiones son tomas en tiempo oportuno. El otro $26 \%$ consideran que sus jefes no los toman en cuenta para tomar algunas decisiones de la empresa.

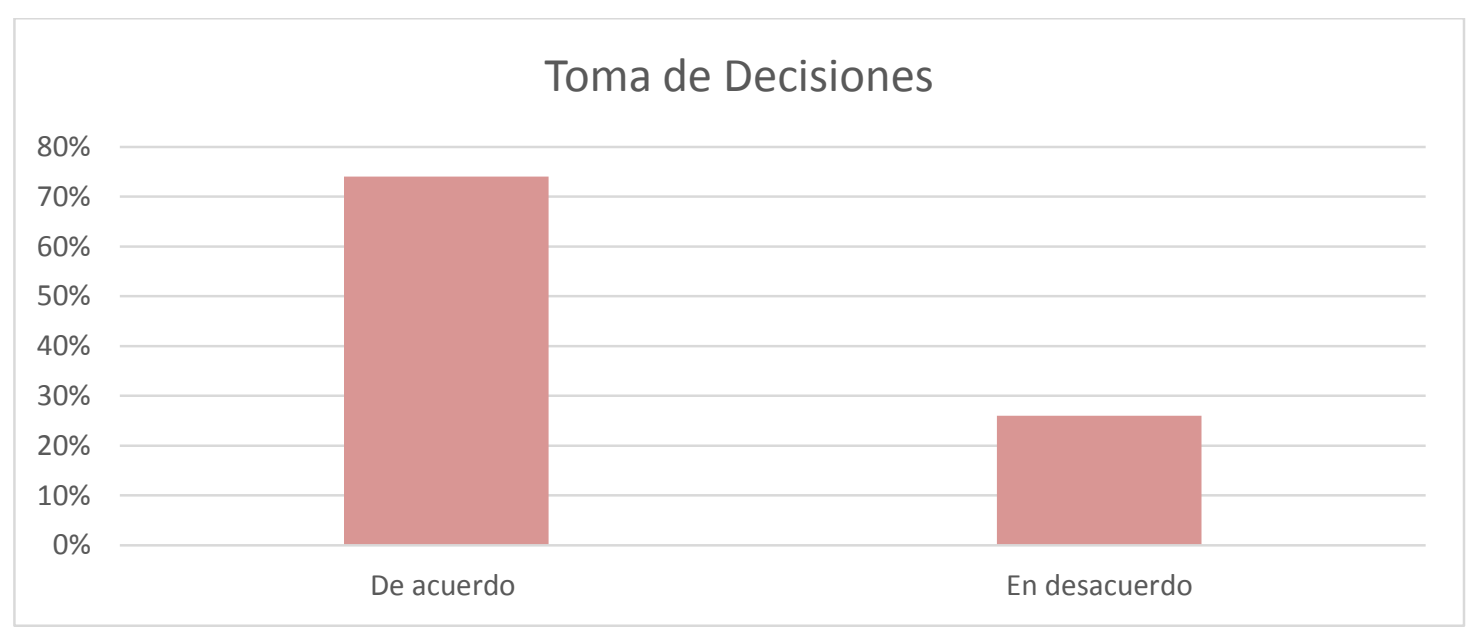

Tabla 6 Toma de Decisiones 


\section{http://revistainvestigacionacademicasinfrontera.com}

Actualmente en el mundo las empresas privadas o públicas se preocupan más por el recurso humano, las organizaciones están obligadas a mostrar un mayor interés en la calidad de vida de sus empleados, ya que ellos pasan la mayor parte de su tiempo donde laboran, y se preocupan por que los estos se sientan cómodos en su ambiente de trabajo y den lo mejor de sí, para que sean más eficientes.

De acuerdo a los resultados de la investigación puede afirmarse que existe coincidencia con estudios realizados con anterioridad como el de Pelekais, Navay \& Tirado (2006) el cual tuvo como objetivo determinar la influencia de la Inteligencia emocional sobre Clima Organizacional en los niveles gerenciales medios de las PyMES. Los resultados permiten plantear que los elementos evaluados de la Inteligencia emocional que se encuentran presentes en el Clima Organizacional y que en cierta forma lo afectan, se encuentran la motivación y las habilidades sociales.

En la investigación realizada en las PyMES de un centro comercial de la ciudad de Navojoa, Sonora, se encontró cierta similitud, en la dimensión de Motivación, ya que uno de las factores que afectan el clima organizacional en las organizaciones es la Motivación hacia los trabajadores; los cuales en este caso consideran no estar motivados, ya que la empresa no les permite asistir a eventos personales dentro de su jornada laboral, lo que es tomado en cuenta como un limitante importante para su satisfacción personal.

\section{CONCLUSIONES}

A través de la realización de la investigación se pueden evidenciar las características del clima organizacional en las MIPYMES, siendo las de mayor incidencia en los resultados; El 


\section{http://revistainvestigacionacademicasinfrontera.com}

liderazgo, ya que los gerentes que en la mayoría de los casos son los propietarios de las MIPYMES y se convierten en buenos líderes para su propia organización, como es evidente en las empresas que suelen ser pequeñas y no tener tantos trabajadores, es más fácil tener el control de los empleados. De igual manera, otra fue la comunicación ya que al ser empresas con un número reducido de trabajadores la difusión de información se torna más sencilla, así como el contacto con los empleados lo cual permite darles a conocer, la misión, visión y valores de la empresa. Por otra parte la organización es una de la característica que se considera en el clima organizacional, considerando que en ese tipo de empresas los trabajadores identifican fácilmente el área donde se encuentran.

Conocer el clima organizacional es relevante para cualquier organización ya el comportamiento de los trabajadores y el ambiente donde laboran afecta en el rendimiento del personal, la existencia de un clima organizacional favorable condiciona una mayor calidad de vida para trabajadores de todos los niveles en las MIPYMES de un centro comercial de la ciudad de Navojoa, Sonora. Adicionalmente puede afirmarse que las MIPYMES son motor de crecimiento y desarrollo local y regional.

\section{RECOMENDACIONES}

En base a los resultados determinados en la investigación pueden plantearse recomendaciones que enriquezcan el desarrollo de las MIPYMES analizadas.

Las dimensiones más vulnerables fueron las de toma de decisiones y motivación, de manera específica los empleados consideran que no es tomado en cuenta su punto de vista al tomar decisiones dentro de la empresa. Realizar reuniones periódicas de trabajo en donde se informe de manera formal al personal la toma de decisiones de la empresa, como estrategias 
Julio- Diciembre 2017

Año 10.

Revista de Investigación

Núm. 26

Académica sin Frontera

ISSN: 2007-8870

\section{http://revistainvestigacionacademicasinfrontera.com}

de venta, capacitación, inversión recurso humano entre otros, así como tomar en cuenta su punto de vista en cada uno de estos aspectos.

En el caso específico de la motivación el personal considera que es necesario mayor apertura por parte de los gerentes al permitirles asistir a eventos personales, una estrategia sugerida en este caso es establecer un número de días de permiso al año que el empleado pueda utilizar a su consideración para atender asuntos personales, lo cual permitirá se eleve el grado de satisfacción laboral por parte del personal.

De manera general se recomienda a las organizaciones analizadas mantener los niveles obtenidos en cada una de las dimensiones de clima organizacional, así como implementar estrategias que permitan mejorar cada uno de los puntos más débiles en esta materia, ya que el percibir un clima organizacional agradable y trabajar con un grupo de trabajo, donde exista, comunicación, respeto y cooperación incide favorablemente en los resutados de las organizaciones. Por lo tanto realizar mediciones en el clima organizacional es un factor de suma importancia a considerar en las empresas en forma particular en las MIPYMES ya que impacta directamente en el desarollo de la sociedad.

\section{Bibliografía}

Brunet, L. (2007). Definición, diagnóstico y consecuencias. Mexico D.F. Editorial Trillas. 


\section{Julio- Diciembre 2017}

Año 10.

Revista de Investigación

Núm. 26

Académica sin Frontera

ISSN: 2007-8870

\section{http://revistainvestigacionacademicasinfrontera.com}

Hellrieger, D., \& Slocum, J. (1974). “Organizational Climate: Measures, research and Contingencies”, The Academy of Management Journal pp 255-280. (Vol. 17).

Ibarra, P. R. (2013). Diseño y validación de un instrumento para evaluar el clima organizacional en las PYMES. Intituto Tecnologico de Sonora.

Margarita Chiang Vega, M. J. (2010). Relaciones entre el clima organizacional y la satisfacción laboral. madrid: R.B servios editoriales S.L.

Mendez, C. (2006). Clima organizacional en Colombia. El IMCOC: Un método de análisis para su intervención. Colección de lecciones en administración. Bogotá, Universidad del Rosario.

Schneider, B. S.-J.-1. (1994). Creating the climate and culture of success. Organizational Dynamics (Vol. 24).

Münch, L. y Ángeles, E. (2007). Métodos y técnicas de investigación. México: Editorial Trillas S.A. de C.V. Pág. 167.

García, M. y M. Bedoya (1997). Hacia un Clima Organizacional Plenamente Gratificante en la División de Admisiones y Registro Académico de la Universidad del Valle, Universidad del Valle. Tesis de grado de Maestría.

Priscilia Rossel Amarillas Ibarra (2013). Diseño y validación de un instrumento para evaluar el clima organizacional en las PYMES”.Instituo Tecnologico de Sonora. Tesis de grado de Maestría.

García, M. y Zapata D., A. (2008). Instrumento para el diagnostico del clima organizacional.

Universidad del Valle. Facultad de Ciencias en la administración. Santiago de CaliColombia. Documento inédito 


\section{Julio- Diciembre 2017}

Año 10.

Revista de Investigación

Núm. 26

Académica sin Frontera

ISSN: 2007-8870

\section{http://revistainvestigacionacademicasinfrontera.com}

García, O. (1987). Un Modelo para el Autodiagnóstico del Clima Organizacional. Revista Tecnología Administrativa. Volumen V. Número 12 Mayo - Agosto. Medellín.

Cira de Pelekais, Angel Nava \& Luis Tirado (2006). Inteligencia emocional y su influencia en el clima organizacional en los niveles gerenciales medios de las PYMES. Pag.286

Jesús F. Salgado, Carlos Remeseiro \& Mar Iglesias (1996). CLIMA ORGANIZACIONAL Y SATISFACCIÓN LABORAL EN UNA PYME. Pag.333

Instituto Nacional de Estadística y Geografía. (2016). Directorio Estadístico Nacional de Unidades Económicas. Obtenido de INEGI: http://www.beta.inegi.org.mx/app/mapa/denue 